O August 10, on the beach at Cape Canaveral in Florida, I saw a redheaded man, sunburned to look like a boiled lobster, applying novocaine cream to his glowing back. The only unusual circumstance was that the man was Mike McElroy, whose field is the physics and chemistry of planetary atmospheres and who has loudly warned us against the ultraviolet perils of destroying the ozone layer by using aerosol spray cans. Aha, I thought: one foot in the sea, and one on the shore-to one thing constant never. For surely he, of all people, should have kept his shirt on.

The proposed ban on aerosol spray cans is a model of scientific virtue. It will save the sacred Environment of our fragile space-ship Earth from the excesses of rampant technology. It will prevent cancer. It will enable academic atmospheric physicists to cover themselves with glory-their abstruse field is Being Put To Use, while visions of research grants dance through their heads. Investigation of the subject is "a natural" for the techniques, instrumentation and vehicles of the space programme, and so it will be a firstrate spin-off for NASA. The ban may even save some metal from being used in cans, and it will benevolently force people to use their flabby muscles in wielding paint brushes. The New York Subway System will perhaps be able to clean up its cars, which are now hideously festooned with paint applied from spray cans by the vandals who also deface rocks by the roadside. Spray-on armpit deodorants will be replaced by the roll-on type, and the consumer will pay the same astronosome aluminium salt to close the polating to come up with the figure of axillary sweat glands. Furthermore, no
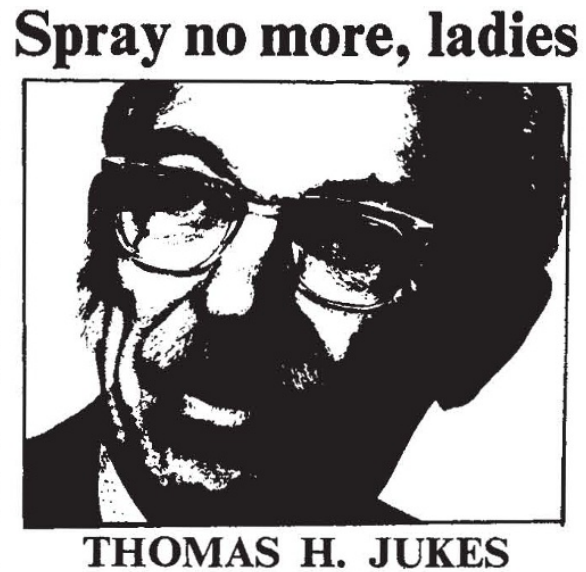

the effect of aerosols on the ozone layer is a matter of debate rather than measurement. And then, of course, ultraviolet light protects against rickets. ... If the danger of cancer from solar ultraviolet light is so great, why not suggest that people keep their clothes on? From Sydney to Stockholm, the near-naked and naked whiteskinned legions loll on beaches, seeking to acquire the shadowed livery of the burnished sun, and to hell with skin cancer.

A few cynical sceptics remain unconvinced. Professor Richard Scorer says it is Much Ado About Nothing. $\mathrm{He}$ has been rude enough to say that the talk of the threat to the ozone layer is a publicity gimmick concocted by doomsayers using scare tactics to gain headlines, and that most of the organic chlorine compounds now measured in the stratosphere are of natural origin, or from the deliberate burning of vegetation. Personally, I rather favour his thesis that the environment is full of checks and balances, and "is not as frail as some people picture it". But heaven forbid that I should suggest that a large amount of research on this latest scare is not needed; it will train young scientists, and it will help to restore badly needed public confidence in the social values of research in the natural sciences.

And perhaps-who knows? - we may eventually be able to ride on the New York Subway, and read the advertisements for deodorants unmarred by paint from aerosol spray cans! But I am afraid that I underestimate the ingenuity of industrial chemists, who undoubtedly are hard at work to devise new spray propellants that do not destroy ozone, thus converting all our sounds of woe to hey-nonny-nonny.
THE first protocol of the Anglo-Soviet Joint Commission on Health Cooperation, signed on September 25, 1975 by Mrs Barbara Castle, Secretary of State for the Social Services, and Professor Boris Petrovskii, Soviet Minister of Health, represents the first stage in the implementation of the Anglo-Soviet Agreement on Cooperation in Medicine and Public Health which resulted from Mr Harold Wilson's visit to Moscow last February.

The agreement itself is a wide ranging document, dealing in general terms with "exchanges of information on new equipment, pharmaceutical products and technological developments related to medicine and public health," reciprocal health-service arrangements for British and Soviet citizens requiring immediate medical treatment while in the other country, and the elaboration of (so far unspecified) programmes of

\section{Healthy exchanges}

from Vera Rich, London

joint research. Only one sectionArticle 2A-names any specific subjects for cooperation, and it is precisely these, influenza and other communicable diseases, ophthalmic diseases, and the organisation of medical care for traumatic and cardiac emergencies, which are the subject of the present Protocol.

Under the terms of the Protocol up to 25 man-months during the first year of its operation may be spent by each side on research in the other's country, with due arrangements made for the supervision of research and the pooling of results. The institutions involved in the exchange will be the
Institute of Opthalmology of the University of London and the All-Union Institute of Ophthalmic Diseases; the Public Health Laboratory Service, Colindale, and the Moscow Institute for Virus Preparations; and the Medical Research Council Accident and Burns Unit, Birmingham, and the Moscow Institute for Emergency Medical Services.

Although the agreement makes provision for sending patients for treatment from one country to the other the Protocol stresses that in view of the "high level of development" of both health services, such exchanges are envisaged in exceptional circumstances only, and it seems likely that cases such as that of the Russian baby Irina Chudnovskaya, who has already been treated at the Brompton Hospital for a heart condition, will remain relatively rare. 